\title{
Dynamic modelling of solids in a full-scale activated sludge plant preceded by CEPT as a preliminary step for micropollutant removal modelling
}

\author{
Zeina Baalbaki ${ }^{1} \cdot$ Elena Torfs $^{2} \cdot$ Thomas Maere $^{2} \cdot$ Viviane Yargeau $^{1}$. \\ Peter A. Vanrolleghem ${ }^{2}$
}

Received: 19 November 2016/Accepted: 25 November 2016

(C) Springer-Verlag Berlin Heidelberg 2016

\begin{abstract}
The presence of micropollutants in the environment has triggered research on quantifying and predicting their fate in wastewater treatment plants (WWTPs). Since the removal of micropollutants is highly related to conventional pollutant removal and affected by hydraulics, aeration, biomass composition and solids concentration, the fate of these conventional pollutants and characteristics must be well predicted before tackling models to predict the fate of micropollutants. In light of this, the current paper presents the dynamic modelling of conventional pollutants undergoing activated sludge treatment using a limited set of additional daily composite data besides the routine data collected at a WWTP over one year. Results showed that as a basis for modelling, the removal of micropollutants, the Bürger-Diehl settler model was found to capture the actual effluent total suspended solids (TSS) concentrations more efficiently than the Takács model by explicitly modelling the overflow boundary. Results also demonstrated that particular attention must be given to characterizing incoming TSS to obtain a representative solids balance in the presence of a chemically enhanced primary treatment, which is key to predict the fate of micropollutants.
\end{abstract}

Electronic supplementary material The online version of this article (doi:10.1007/s00449-016-1715-5) contains supplementary material, which is available to authorized users.

Zeina Baalbaki

zeina.baalbaki@mail.mcgill.ca

1 Department of Chemical Engineering, McGill University, 3610 University St., Montreal, QC H3A 0C5, Canada

2 modelEAU, Département de génie civil et de génie des eaux, Université Laval, 1065 Avenue de la médecine, Quebec, QC G1V 0A6, Canada
Keywords Activated sludge modelling · Conventional pollutants · Contaminants of emerging concern · Influent characterization $\cdot$ Solids balance

\section{Introduction}

Conventional pollutant modelling in activated sludge wastewater treatment plants (WWTPs) has been carried out for purposes of design and control [1, 2], optimization $[3,4]$, process upgrades [5] and for evaluation of greenhouse gas emissions [6]. Such modelling activity involves purpose-dependent calibration of models representing the bioreactor and the settler, which are the two essential constituents of an activated sludge plant. A series of activated sludge models (ASMs) have been developed by Henze et al. [7] as a tool to model bioreactors, and the implementation of these models for dynamic modelling of conventional activated sludge units began in the late 1970s [8].

In addition to the bioreactor model, a representative secondary settler model is essential for accurate modelling of the bioprocesses in the bioreactors as the return sludge from the settler influences the solids balance in the whole system [8]. The 1-D 10-layer Takács model [9] has long been the most widely used model to describe the settling dynamics in secondary settlers. A more advanced model was developed later, the Bürger-Diehl model [10, 11], that calculates the flux between the layers in a more mathematically sound way, as well as allows the addition of compression settling (i.e. settling due to compressive forces) and inlet dispersion (i.e. mixing around the inlet region). This model also explicitly takes the overflow and underflow boundaries into account to better represent the flows leaving the settler $[10,11]$. The Bürger-Diehl model 
was applied by Torfs et al. [12], and its benefits over the Takács model were discussed in the same study. Besides the selection of a suitable settler model, proper characterization of incoming solids in terms of model components is essential to achieve a proper solids balance [13]. Proper characterization of the influent organics is also essential, as it affects the system's solids mass balance. Characterization of incoming solids can be either based on chemical oxygen demand (COD) or total suspended solids (TSS) measurements [13]. There is currently, however, little information in the literature on the impact of the chemically enhanced primary treatment (CEPT) preceding the activated sludge treatment on the solids composition in the input stream to the activated sludge unit.

Investigating the fate of micropollutants of emerging concern, such as pharmaceuticals, personal care products and hormones in conventional wastewater treatment processes has been gaining attention due to their presence in ecosystems and their proven adverse effects on the aquatic environment [14]. Several models have been built to predict the fate of different types of micropollutants in WWTPs [15-19]. Among these efforts is the extension of the ASM No. 2d model, which is among the commonlyused ASMs [7], under the ScorePP Project to include the fate of micropollutants [19]. The main processes considered to influence the fate of micropollutants in WWTPs are biodegradation, sorption, photolysis, volatilization and hydrolysis [20]. The extent to which these processes remove micropollutants from wastewater depends on a number of conditions, including the oxygen supply that affects volatilization, the solids concentration that affects adsorption, as well as the solids retention time (SRT) that influences the diversity of biomass and the presence of slowly growing microorganisms, both of which are associated with a higher degree of micropollutant biodegradation [21, 22]. For example, the presence of nitrifying biomass, which is one type of slowly growing microorganisms, has been shown to correspond to improved biodegradation of micropollutants [22]. The abundance of nitrifying biomass can be indicated by the removal of its main substrate, ammonia. In this context, it is important to stress that if the goal of the modelling exercise is to model micropollutants, it is not necessary to predict the detailed diurnal variations in the concentration of ammonia, but it suffices to capture the general ammonia removal in order to get a proper estimate of the nitrifying biomass. Hence, the emphasis of the conventional pollutants calibration exercise should be adapted to its final goal (i.e. supporting proper modelling of the fate of micropollutants in this context).

This paper presents a procedure for the calibration of a conventional activated sludge model based on standard data available from WWTPs (i.e. with a minimal additional sampling effort) for the specific objective of a subsequent development and calibration of a micropollutant model that is tackled in another study. The conventional pollutant modelling involved hydraulic modelling of the WWTP, selection of a bioreactor and a settler model and subsequent calibration of the submodels. Particular emphasis was put on the prediction of the overall profile of oxygen concentration, the solids inventory and the solids retention time (SRT) as these are the most important variables influencing the micropollutant removal processes. The modelling approach also aimed at providing insights on the characterization of incoming wastewater when modelling activated sludge systems that are preceded by CEPT.

\section{Methodology}

\section{WWTP}

The WWTP under study is located in Guelph, Ontario. The main characteristics of this WWTP are summarized in Table 1, and the schematic of the WWTP is presented in Fig. 1. Preliminary treatment is achieved by screening and aerated grit removal, after which ferric chloride (37-45\%) is added at a rate of $1 \mathrm{~L} \mathrm{~min}^{-1}$ and the load is split into four treatment lines. Each of these lines consists of two primary clarifiers, two aeration tanks and one or two secondary clarifiers in parallel. The incoming flow rate to each of these lines is different, with line 1 receiving the highest flow. For this paper, only the activated sludge unit (aeration tanks and secondary clarifier) of the first line was investigated. Each of the two parallel aeration tanks (east and west) in line 1 contains three passes in series. The combined effluent of both aeration tanks is directed to one secondary clarifier. Following secondary treatment, the recombined effluent of the lines enters rotating biological contactors (RBCs), followed by sand filtration for tertiary

Table 1 Main characteristics of the studied WWTP, as well as the average hydraulic retention time (HRT), average solids retention time (SRT) and average temperature (T) over 21-24 July 2014 in the first activated sludge line (line 1)

\begin{tabular}{ll}
\hline Characteristic & Treatment stage \\
\hline Population served & 135,000 \\
Design capacity $\left(\mathrm{m}^{3} \mathrm{day}^{-1}\right)$ & 64,000 \\
Average incoming flow rate $\left(\mathrm{m}^{3} \mathrm{day}^{-1}\right)$ & 50,750 \\
HRT (h) & \\
Primary clarifier (line 1) & 3.72 \\
Aeration tanks (line 1) & 6.30 \\
Secondary clarifier (line 1) & 2.90 \\
SRT (days) (line 1) & 7.76 \\
Average T $\left({ }^{\circ} \mathrm{C}\right)$ & 20 \\
\hline
\end{tabular}


treatment. RBCs and sand filtration were installed to ensure that the TSS and ammonia levels at the final effluent meet environmental regulations. The final effluent disinfected by chlorination is discharged into a nearby river.

\section{Data collection}

Flow rates of aqueous and sludge streams exiting line 1 as well as the volumes of the individual units were obtained from the operators at the WWTP. Table 2 gives an overview of the characteristics monitored at the different sampling locations, as well as the frequencies of the measurements. At the primary and secondary effluents, samples were collected by onsite Hach Sigma samplers as daily flow-proportional composites. In the aeration tanks, grab samples were collected for the analysis of the mixed liquor suspended solids (MLSS) and mixed liquor volatile suspended solids (MLVSS). Routine measurements that were performed onsite every few days were acquired from the WWTP over one year and are denoted as "Y" in Table 2. These include chemical oxygen demand (COD), total suspended solids (TSS), total Kjeldahl nitrogen
(TKN) and nitrite and nitrate nitrogen $\left(\mathrm{NO}_{2}\right.$ and $\mathrm{NO}_{3}$, respectively). The remaining measurements, denoted " $\mathrm{S}$ ", were performed in a sampling and measurement campaign performed over three consecutive dry days in July 2014 and include soluble chemical oxygen demand $\left(\mathrm{COD}_{\mathrm{s}}\right)$, 5-day biological oxygen demand $\left(\mathrm{BOD}_{5}\right)$, ammonium nitrogen $\left(\mathrm{NH}_{4}\right)$, total phosphorus $(\mathrm{P})$ and alkalinity. Analysis for all measurements was performed by the onsite lab, following APHA/AWWA protocols outlined by Rice et al. [23]. Online dissolved oxygen concentration (DO) measurements were available from onsite oxygen sensors installed at the first and third pass of both aeration trains. For all output figures (Figs. 2, 3, 4, 5), the time axis begins in July and ends in June the following year, with the winter period falling in the middle of the axis.

\section{Simulation environment and model bases}

Simulations were carried out with the WEST modelling and simulation software (Mike Powered by DHI, Hørsholm, Denmark). The ASM2dTemp model base available in the WEST software was used to describe the bioreactor

Fig. 1 Schematic of the Guelph WWTP. Wastewater streams are represented by continuous lines and sludge streams by dashed lines

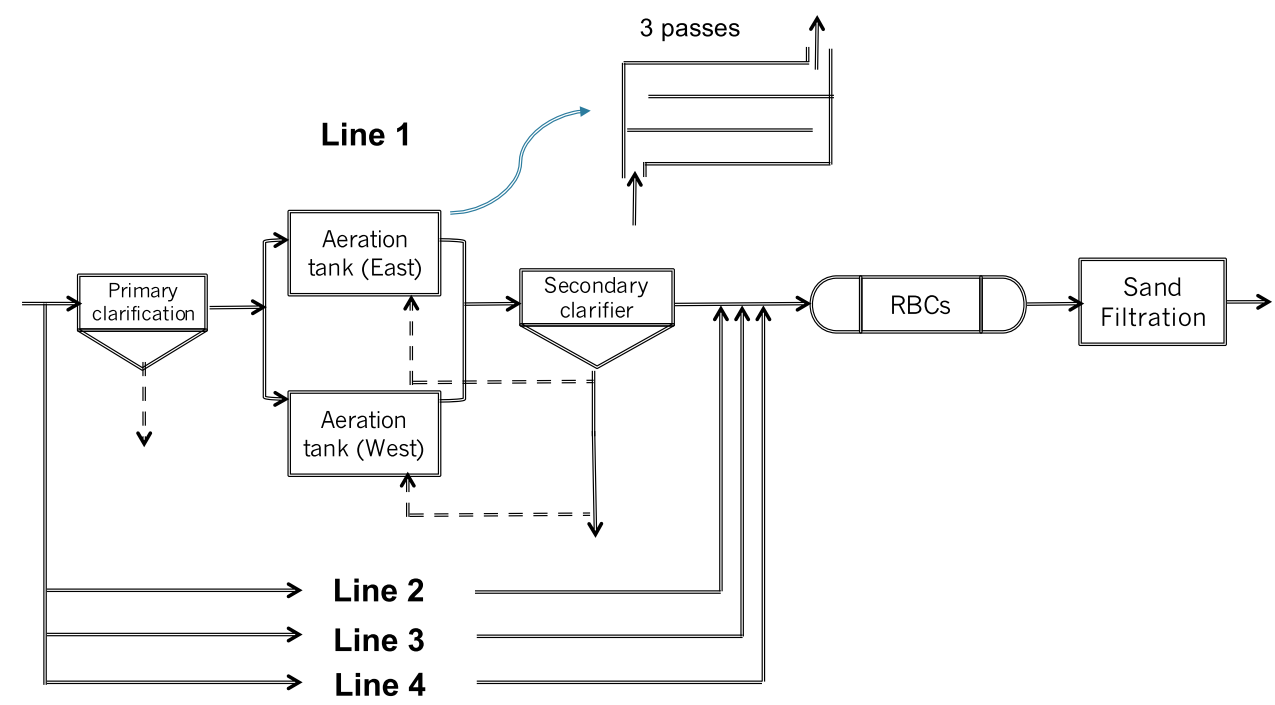

Table 2 Schedule of the monitoring of wastewater characteristics in the primary effluent, the secondary effluent, the waste sludge and inside aeration tanks, including measurements performed frequently over the year $(\mathrm{Y})$ and those performed over a few days in the summer (S) during a more intensive measurement campaign

\begin{tabular}{|c|c|c|c|c|c|c|c|c|c|c|}
\hline Variable & COD & CODs & $\mathrm{BOD}_{5}$ & TSS & TKN & $\mathrm{NH}_{4}$ & $\mathrm{P}$ & Alkalinity & $\mathrm{NO}_{2}$ and $\mathrm{NO}_{3}$ & DO \\
\hline Primary effluent & $\mathrm{Y}(1)^{\mathrm{a}}$ & $\mathrm{S}^{\mathrm{a}}$ & $S$ & $\mathrm{Y}(1)$ & $\mathrm{Y}(2)$ & $S$ & $\mathrm{~S}$ & $S$ & - & - \\
\hline Aeration tanks & - & - & - & $\mathrm{Y}(1)^{\mathrm{b}}$ & - & - & - & - & - & Online \\
\hline Secondary effluent & $\mathrm{Y}(2)$ & $\mathrm{S}$ & - & $\mathrm{Y}(2)$ & $\mathrm{Y}(2)$ & $S$ & - & - & $\mathrm{Y}(2)$ & - \\
\hline Waste sludge & - & - & - & Y (1) & - & - & - & - & - & - \\
\hline
\end{tabular}

${ }^{a}$ S: represents measurements collected over 3 days in the summer of 2014 (July 21-July 24). Y: represents measurements collected from July 2013 to July 2014 with the frequency (times per week) between brackets

b This included MLSS and MLVSS 
processes. For the secondary settler, the widely used Takács all fractions propagator model $[9,24]$ and the more recent Bürger-Diehl model [11] were each tested for the system under study.

\section{Hydraulic calibration}

Hydraulic calibration of the activated sludge unit under study has been performed earlier, and details on the results can be found elsewhere [25]. In brief, HOBO conductivity loggers (Hoskin Scientific, St-Laurent, QC, Canada) were deployed over a period of 3 weeks (12 June-8 July, 2014) at the primary effluent, aeration tank effluent and secondary effluent to collect electrical conductivity data (one reading per minute). The measured conductivity was used as a tracer for the hydraulic calibration, along with the volumes of the treatment units and flow rates. After varying the number of tanks in series and the influent layer of the settlers, the final layout that describes the hydraulic behaviour of the activated sludge was decided based on minimizing the root mean square error (RMSE) between the predicted and the measured conductivity trends. The best-fit model structure consisted of three aeration tanks in series and one secondary clarifier with the feed stream entering at the mid-layer [25]. In the final model structure, it was necessary to separately consider the two parallel trains of aeration tanks (i.e. two parallel trains of three tanks in series) to capture the distinct hydraulic behaviour of each train, since the incoming wastewater and return sludge flow rates are observed to be different for each train.

\section{Influent characterization}

Characterization of the chemical oxygen demand (COD) in the influent was performed following the STOWA guidelines for modelling with ASM [26, 27]. This protocol was chosen over other fractionation protocols (e.g. Melcer et al. [28]) for its simplicity and reduced need of measurements. The COD was fractionated into four main components, as illustrated in Table 3: inert soluble fraction $\left(S_{\mathrm{I}}\right)$, biodegradable soluble fraction $\left(S_{\mathrm{S}}\right)$, slowly biodegradable particulate fraction $\left(X_{\mathrm{S}}\right)$ and inert particulate fraction $\left(X_{\mathrm{I}}\right)$. The differentiation between soluble and particulate material for ASM models is based by

Table 3 The relationship between the measurement and the fractionation of COD and TSS, as well as the modelling of particulates in the ASM2d model. $X_{\mathrm{AUT}}$ and $X_{\mathrm{HET}}$ represent nitrifying and heterotrophic biomass concentration, respectively

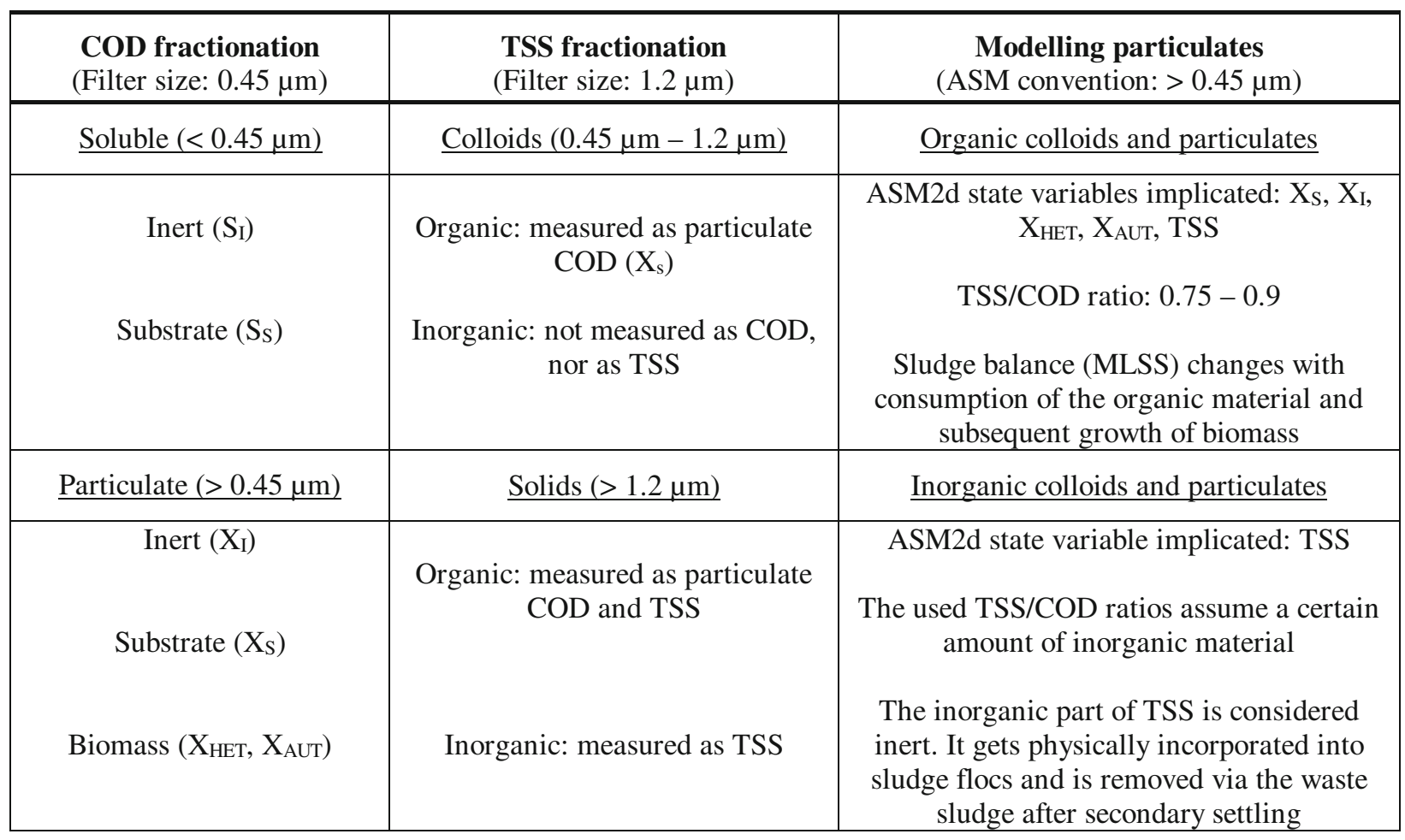


convention on a filter size of $0.45 \mu \mathrm{m}$. Following the STOWA protocol [26, 27], the $S_{I}$ fraction was assumed to be equal to the soluble COD measurement that remains in the effluent. The $S_{\mathrm{S}}$ fraction was obtained by subtracting the inert soluble COD $\left(S_{\mathrm{I}}\right)$ from the measured soluble COD in the influent. The $X_{\mathrm{s}}$ was obtained from the total biodegradable material, which is estimated by the ultimate BOD (i.e. at time infinity) extrapolated from the measured $\mathrm{BOD}_{5}$. Finally, the $X_{\mathrm{I}}$ fraction was found as the difference between the total COD measurement and the previously defined fractions. These calculations were performed over the three dry summer days of the sampling campaign, and the obtained fractions were applied for the whole year.

Details of the TSS fractionation are also illustrated in Table 3. A common approach to fractionate the TSS in the influent to the model is by using the particulate COD concentrations as a basis (e.g. by using a fixed TSS/COD ratio which is by default 0.75 for non-biomass and 0.9 for biomass [7]). This will be referred to as the COD-based TSS. The used influent TSS/COD ratios assume a certain fixed amount of inorganic suspended solids (i.e. iSS, such as minerals) that are not measured as COD [7]. These ratios can be adjusted by the modeller to vary the quantity of iSS that needs to be included to fit the measured output TSS. When the TSS/COD ratios related to the influent fractionation are adapted to account for inorganics, the ratios pertaining to the biological conversion model must not be altered. The inorganic fraction does not take part in the biokinetic processes. It is assumed to be physically incorporated in activated sludge flocs, to remain unchanged during the process and to eventually be removed with the waste sludge after the secondary settling step. As an alternative to the COD-based TSS, characterization of input TSS could also be performed on the basis of TSS measurements. The standard measurement of TSS for wastewater is, however, known to exclude some organic and inorganic colloids due to the used filter size that is larger than the one used for COD analysis (Table 3). Since these colloids attach to activated sludge flocs once inside the bioreactor and thus contribute to the MLSS, the fractionation needs to be adjusted accordingly to account for these colloids. Ideally, both TSS characterization methods (i.e. based on particulate COD and based on TSS measurements) should give the same results, but differences can occur when not properly accounting for colloids and inorganics. In this study, both approaches were considered for the characterization of influent TSS. The way the state variable TSS is standardly incorporated in the ASM2d model accommodates both approaches since, next to the organic fraction of TSS, it also allows to introduce the iSS fraction of TSS.

The characterization of nitrogen $(\mathrm{N})$ and phosphorus $(\mathrm{P})$ in the influent was performed using measurements of total nitrogen and total phosphorus. The nitrogen and phosphorus contained in organic matter were calculated using typical fractions of $\mathrm{N}$ and $\mathrm{P}$ contents in COD provided for ASM2d by Henze et al. [7] and shown in the supplementary materials (Table S1). The ammonia was then calculated as the difference between the total nitrogen (TKN) available from the measurements and the calculated nitrogen content in organic matter throughout the year. The calculated ammonia results were successfully verified over the three days of the sampling campaign during which measurements of ammonia were available.

As shown in Table 2, data for COD and TKN were available at a frequency of one to two measurements per week for a year. However, to increase the resolution of the model, one value per day is needed for the conventional pollutants. For combined sewers, COD and TKN are often correlated with the influent flow, and the correlations can be used to increase the time resolution of the characterized influent if frequent flow data are available [29]. However, analysis of the data for the studied WWTP did not show meaningful correlations between the flow rate and the aforementioned measurements (not shown), which is likely related to its separate sewer system. Therefore, the time resolution of the influent measurements was increased by fitting the less-frequently measured data to a best-fit polynomial function. These polynomials captured the yearly profile of the measurements and allowed interpolation for daily values to be used for input generation. The fits are given in the Supplementary Material (Figure S1). More detailed diurnal patterns of conventional pollutants in the influent were deemed unnecessary given the modelling goal. Thus, the achieved conventional pollutant model should not be evaluated based on sub-daily dynamics.

\section{Simulation approach and calibration}

Preliminary simulations were carried out using the default ASM parameters listed by Henze et al. [30] and default settler parameters suggested in the COST Simulation Benchmark manual [31]. Each dynamic simulation was preceded by a steady simulation for a period equivalent to at least three times the SRT (i.e. 20 days) in order to determine the initial conditions for the dynamic simulation [13].

Model calibration efforts were focused on fitting variables that directly impact the fate of micropollutants, such as dissolved oxygen concentration, solids concentration and nutrients concentration. The first step was the calibration of the oxygen mass transfer coefficient $\left(k_{\mathrm{L}} a\right)$ to match the measured DO, which was in general observed to be abundant (i.e. average $>5 \mathrm{mg} \mathrm{L}^{-1}$ ). The second step involved achieving a match between the simulated and the measured TSS concentrations at different locations in the activated sludge process, such as the waste sludge (i.e. 
WAS TSS), the aeration tank (i.e. MLSS) and the secondary effluent (i.e. effluent TSS). The solids balance was first pursued by calibrating the settling parameters. Results of this initial calibration work could give an indication as to whether adjusting the settling parameters is sufficient to obtain the correct solids balance, or if, alternatively, characterization of the input solids is the appropriate approach for achieving the solids balance. The third step involved achieving an agreement with measured nutrients: $\mathrm{NH}_{4}$ (and its product $\mathrm{NO}_{3}$ ), as well as COD. This last step can depend on several biokinetic parameters such as growth rates, decay rates and substrate affinities. However, for a conventional activated sludge process, these parameters are relatively well known [30], and large calibration efforts should be avoided. That is because discrepancies between model predictions and measurements that require the calibration of these parameters may indicate other underlying calibration problems related to the hydraulic model or the solids balance.

The parameters that correspond to each step were varied using the scenario analysis tool in WEST software, and the best-fit model was decided upon by visual inspection. While the simulations were set to provide hourly values of the output variables, the measurements of the same variables were based on daily flow-proportional samples. Therefore, it was necessary to calculate the daily flow-average of the simulated results using the equation: $\bar{C}=\sum Q_{\mathrm{i}} C_{\mathrm{i}} / \sum Q_{\mathrm{i}}$, where $\bar{C}$ represents the flow-average concentration, $Q_{\mathrm{i}}$ and $C_{\mathrm{i}}$ represent the flow rate and the simulated output concentration at a certain time point " $i$ ". This provided simulated values with similar time scale as the experimental measurements for the purpose of comparison.

\section{Results and discussion}

The first step towards the calibration of the conventional pollutant model is the characterization of the influent wastewater. This was followed by calibration of the model for the prediction of the dissolved oxygen concentration followed by solids concentration, including characterization of influent solids and finally, model calibration with respect to the nutrient concentrations.

\section{Wastewater characterization}

The recorded flow rates throughout the year seemed to be stable due to the mostly separate sewer system (i.e. with very few combined sewers), which is expected to reduce the seasonal variations in flow rates due to the seasonal variations in rainfall. The recorded temperatures varied from 15 to $22{ }^{\circ} \mathrm{C}$ throughout the year. The measured COD concentration trends showed an increase in winter
Table 4 COD composition (\%) for the primary effluent wastewater under study, determined following the STOWA protocol [26]

\begin{tabular}{llll}
\hline$S_{\mathrm{I}} / \mathrm{COD}$ & $S_{\mathrm{S}} / \mathrm{COD}$ & $X_{\mathrm{S}} / \mathrm{COD}$ & $X_{\mathrm{I}} / \mathrm{COD}$ \\
\hline 6.8 & 37.7 & 21.5 & 34.0 \\
\hline
\end{tabular}

compared to the summer, which might be due to increased degradation of COD in the sewers and primary clarifier at the higher temperatures in the summer. It is important to note that the primary clarifier of this plant has a long retention time of almost $4 \mathrm{~h}$ (Table 1), making that degradation in the clarifier more significant than in typical primary clarifiers. On the other hand, the incoming ammonia concentrations to the activated sludge unit under study showed no significant seasonal variation throughout the year. This could be attributed to the absence of nitrogen removing processes in the mostly anaerobic conditions of a sewer system and primary clarifier. In addition to ammonia, the TSS profile did not show variation over the 1-year period. The measured TSS values had an average value of $70 \mathrm{~g} \mathrm{~m}^{-3}$ in the primary effluent, which corresponds to a TSS reduction of $84 \%$ in the primary clarifier. This TSS reduction is larger than the typical reduction of 40-60\% [32] in primary clarifiers, likely because of the chemically enhanced settler that is known to achieve high TSS removal. The incoming TSS characterization is further discussed in the "Solids calibration" Section.

Table 4 summarizes the fractions of the incoming COD obtained over the three days of the sampling campaign and applied for the whole year. It should be noted that the extra measurements used for obtaining these fractions over three days in the summer fall on the same fitted polynomial that describes the data over the full year (i.e. Figure S1). This indicates that there were no special events on these days that could affect the wastewater composition. Typically, the biodegradable material contained in the primary effluent is predominantly particulate (i.e. slowly biodegradable material) rather than soluble [30]; however, the characterization results shown in Table 4 indicated more biodegradable matter in the soluble phase than in the particulate phase $\left(S_{\mathrm{S}}>X_{\mathrm{S}}\right)$. This could be attributed to two main factors. First, the higher TSS reduction known to occur in chemically enhanced primary clarifiers contributes to the low fraction of particulates in the primary effluent. Second, hydrolysis could occur prior to the aeration tanks due to the long hydraulic retention time (HRT) of the primary clarifier $(3.72 \mathrm{~h})$, which thus permits the conversion of the slowly biodegradable COD (particulate) into readily biodegradable COD (soluble).

\section{Dissolved oxygen calibration}

The average dissolved oxygen over one year was $5 \mathrm{mg} \mathrm{L}^{-1}$ for the first pass (pass 1) and $7 \mathrm{mg} \mathrm{L}^{-1}$ for pass 3 of both 
aeration tanks (i.e. east and west), indicating excessive aeration in the system under study. The oxygen mass transfer coefficient $\left(k_{\mathrm{L}} a\right)$ was estimated in order to reach a match between the simulated and the measured dissolved oxygen in each aeration tank. An initial guess of the $k_{\mathrm{L}} a$ was made by implementing DO controllers that were set to reach the average measured DO by varying the $k_{\mathrm{L}} a$ value. The $k_{\mathrm{L}} a$ values were estimated to be 8.6 and $11 \mathrm{~h}^{-1}$ for the east and west aeration trains, respectively. Dynamic simulations with these $k_{\mathrm{L}} a$ values yielded DO values that are in agreement with the measurements over the whole year, further verifying the validity of the calibrated $k_{\mathrm{L}} a$ values. The estimated $k_{\mathrm{L}} a$ was higher in the west aeration train than in the east train although the measured DO values were similar in both trains and both trains had the same volume and similar MLSS concentration. This higher $k_{\mathrm{L}} a$ in the west train may be attributed to the higher primary effluent and return sludge flows directed towards the west train, which leads to higher oxygen demand and thus a need for a higher oxygen transfer rate to achieve a DO concentration that is similar to that in east train. From both measurements and simulations, it was observed that the DO was higher in pass 3 than in pass 1 for each aeration tank. This spatial variation in the DO throughout the passes could be explained by the fact that while the supplied oxygen is the same in all passes, the incoming load undergoes biodegradation in pass 1 first, leaving less substrate (i.e. less chemical oxygen demand) in pass 3 , which results in a lower oxygen consumption rate.

\section{Solids calibration}

Reaching a proper solids balance by achieving a match between the measured and simulated TSS in aeration tank (i.e. MLSS), and more importantly, TSS in the waste sludge (i.e. WAS TSS) is an essential requirement for predicting the fate of micropollutants. This is explained by the fact that the WAS TSS impacts the extent of micropollutant removal by adsorption, as well as the SRT that influences the extent of micropollutant biodegradation [21].

\section{Initial simulations}

For the purpose of initial simulations, the TSS in the influent was characterized based on particulate COD concentrations according to the typical approach and using typical TSS/COD ratios suggested by Henze et al. [7]. However, the results obtained using this approach showed simulated MLSS concentrations that were higher and contained more seasonal variations throughout the year compared to the measured MLSS that showed no seasonal variation (Fig. 2a, Case A). A similar discrepancy between simulation results and measurements was observed for the TSS in the secondary waste sludge (results not shown). This discrepancy in the solids balance was concluded to be caused by the mischaracterization of the incoming solids to the activated sludge system. This was further supported by the fact that manipulating the settler's parameters failed to achieve a correct solids balance and to capture the actual WAS TSS and MLSS concentrations. To remediate the discrepancies in the solids balance and to achieve an agreement between the simulated and the measured MLSS and WAS TSS concentrations, the characterization of incoming solids was analysed in more detail.

\section{Characterization of incoming solids}

As discussed earlier, the COD-based TSS concentration (i.e. input TSS calculated using TSS/COD conversion factors) showed seasonal variation, similar to the COD, resulting in a seasonally variable MLSS time series, unlike the measured MLSS profile (Fig. 2a). In addition, the average simulated MLSS was observed to be higher than the measured MLSS using the COD-based TSS in the input. In fact, unlike the measured COD, the measured TSS did not show any seasonal variations throughout the year, indicating that the TSS/COD ratio is not constant throughout the year. The presence of the CEPT might cause seasonal alterations to the actual TSS/COD ratio (i.e. caused by changes in the chemical efficiency and solids settling as a result of temperature variation [33]), indicating that the typical ratios used for the calculations of the CODbased TSS in the primary effluent [7] may not be valid and that an alternative route for TSS characterization is required. Therefore, simulations were carried out using the measured TSS as an input, which was found to yield a simulated MLSS profile that, as desired, did not show seasonal variations, but that was lower than the measured MLSS and in almost perfect agreement with the measured MLVSS time series, as shown in Fig. 2b. The latter indicated that a fraction of the input suspended solids was not properly accounted for in the fractionated influent. As mentioned earlier in the "Influent characterization" Section, the measured TSS does not account for organic and inorganic colloidal matter, which results in the underestimation of the actual TSS in the influent [30]. To remedy this, the TSS at the input was scaled up by a ratio of 1.35 , which was shown to lead to satisfactory predictions of the MLSS in the bioreactors and TSS in the secondary waste sludge (Figs. 2c, Fig. 3, respectively). This obtained ratio between the calibrated and the measured TSS in the input to activated sludge treatment is slightly lower than that reported by Henze et al. [30] for an ASM2d model (i.e. 1.5). The lower ratio in the present study is suggested to be attributed to the presence of the CEPT that may reduce the 
Fig. 2 Measured and predicted MLSS concentrations. The latter was obtained using the Takács model and standard settling parameters: Case A: CODbased TSS in the influent, Case B: Measured TSS in influent, Case C: $1.35 \times$ measured TSS in the influent. The time axis is from July 2013 to June 2014
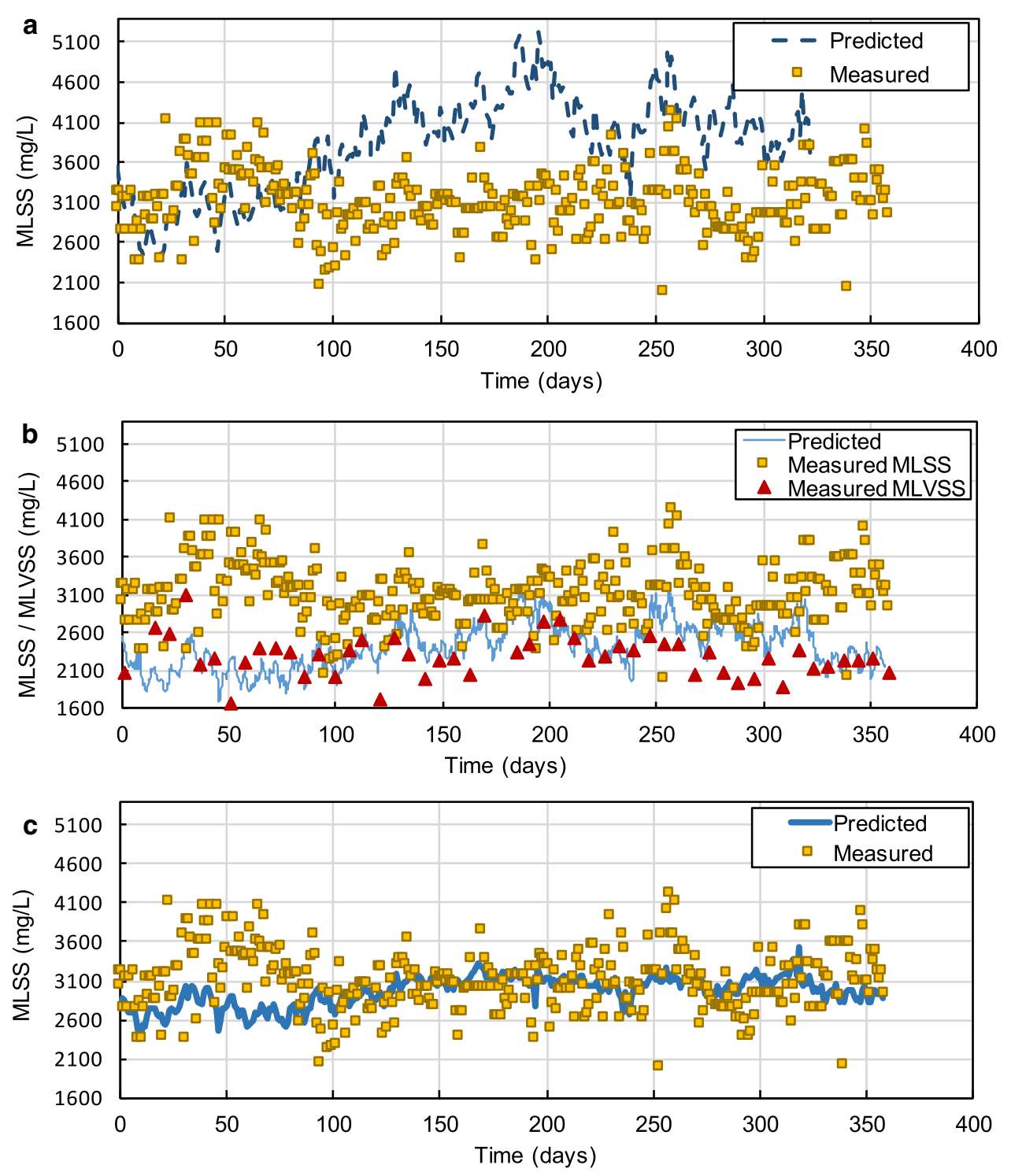

Fig. 3 Measured and predicted TSS concentrations in waste sludge (WAS TSS) after input solids characterization. The time axis is from July 2013 to June 2014

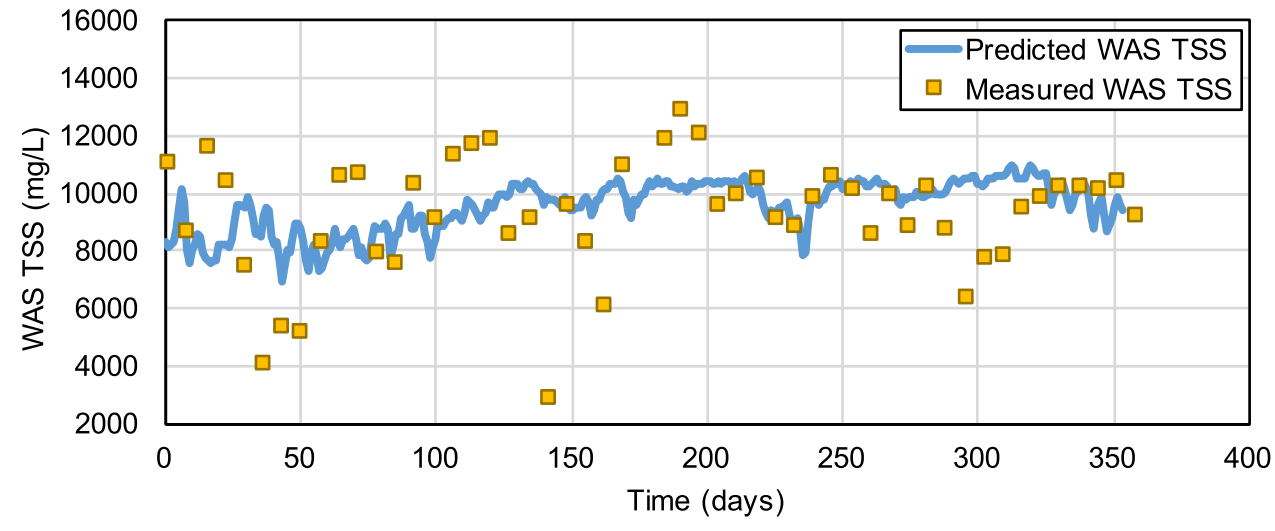

colloidal fraction with a higher efficiency than a conventional primary clarifier, requiring a smaller correction for TSS compared to conventional primary clarification. In fact, it was previously shown that a well-operated CEPT is capable of almost completely removing colloidal material [34-37]. 


\section{Calibration with respect to effluent TSS}

Once the MLSS and WAS TSS were successfully matched, the settling model was further calibrated to predict the TSS concentration in the effluent. Predicting the TSS in the secondary effluent is essential for the subsequent prediction of adsorbed micropollutants in the secondary effluent stream, as well as to properly calculate the SRT, which determines the micropollutant biodegradation capacity of the sludge. Both the Takács and the Bürger-Diehl settler models were tested as shown in Fig. 4 with the combination of parameter values summarized in Table 5. Although the Bürger-Diehl model allows for including the compression and the dispersion phenomena, the low measured sludge volume index (SVI) values (i.e. average of $58 \mathrm{~mL} \mathrm{~g}^{-1}$ ) indicated sludge with very good settling and thickening properties, making it reasonable to assume that compression settling does not play a significant role in the system under study. Accounting for dispersion, which is another phenomenon included in the Bürger-Diehl model and expressed as a function of the input flow rate, was deemed unnecessary. This is explained by the absence of significant flow variations in the input to the activated sludge unit, due to the presence of a separate sewer system. Using the Takács model with the default values for the settling parameters, the simulated TSS in the effluent was observed to be much higher than the measured one, as shown in Fig. 4 (Takács A). Lowering the simulated effluent TSS to match the measured profile was achieved by increasing the $r_{\mathrm{P}}$ parameter (i.e. from 2.86 to $7 \mathrm{~L} \mathrm{~g}^{-1}$ ) and lowering the f-ns parameter (i.e. from 2.28 to 0), as shown in Fig. 4 (Takács B). The observed impact of varying these parameters is explained by the fact that lowering the f-ns leads to a lower fraction of non-settleable solids decreasing the effluent TSS, while a higher $r_{\mathrm{P}}$ value increases the settling velocity and, therefore, decreases the TSS in the effluent.

On the other hand, when using the Bürger-Diehl model, the simulated TSS profile is lower than the profile obtained using the Takács model for default parameter values (Bürger-Diehl A vs. Takács A, Fig. 4). Even though both compression and dispersion of the Bürger-Diehl model were turned off, the better prediction is explained by the existence of two extra top layers in the Bürger-Diehl model that account for the flux over the outlet boundary. Using a larger number of layers in the Bürger-Diehl model (30 layers) as compared to the 10-layer Takács model was also anticipated to result in more representative effluent solids concentrations by diminishing numerical dispersion. Since an agreement between the measured and simulated effluent TSS was not yet achieved using default parameters, the $r_{\mathrm{P}}$ parameter was adjusted to $5 \mathrm{~L} \mathrm{~g}^{-1}$, which resulted in a match between the measurements and simulations (Fig. 4, Bürger-Diehl B). This indicated that a less extensive calibration was required for the Bürger-Diehl model (i.e. only one parameter) compared to the Takács model in order to match the effluent TSS measurements. This justified the use of this model for the settler rather than the Takács model. The fit of the final model for effluent TSS is shown in Fig. 4 (Case Bürger-Diehl B).

\section{Nutrients calibration}

As shown in Fig. 5, once the model was able to accurately predict the solids balance, the effluent nutrient and COD predictions were on average in good agreement with the measurements, keeping in mind the goal of the modelling, without performing any further calibration of biokinetic parameters. In particular, the slightly reduced nitrification by the end of the winter (i.e. between days 200 and 300 on Fig. 5) was well captured by the calibrated model. This emphasizes the importance of obtaining the correct hydraulic model and solids balance before modifying the biokinetic parameters. The simulated COD (Fig. 5) did not show the same fluctuations as the measured values, but the

Table 5 Parameter values tested for each of the settler models (Takács and Bürger-Diehl). Results corresponding to these cases are shown in Fig. 4

\begin{tabular}{llll}
\hline Case & $r_{\mathrm{H}}\left(\mathrm{L} \mathrm{g}^{-1}\right)$ & $r_{\mathrm{P}}\left(\mathrm{L} \mathrm{g}^{-1}\right)$ & $\mathrm{f}-\mathrm{ns}(\%)$ \\
\hline Takács A (default) & 0.576 & 2.86 & 2.28 \\
Takács B & 0.576 & 7 & 0 \\
Bürger Diehl A & 0.576 & 2.86 & 2.28 \\
Bürger Diehl B & 0.576 & 5 & 2.28 \\
\hline
\end{tabular}

Fig. 4 Comparison of predicted effluent TSS concentrations obtained using the Takács and Bürger-Diehl settler models with different parameters (Table 5). The time axis is from July 2013 to June 2014

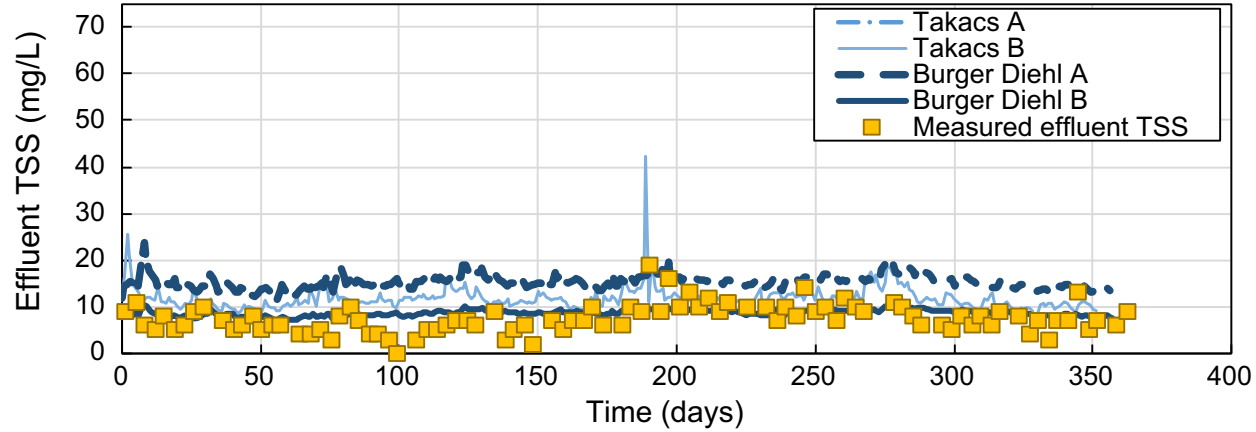


Fig. 5 Measured and predicted conventional pollutant concentrations: a nitrate, b ammonia and c COD in the secondary effluent using the best-fit model. The time axis is from July 2013 to June 2014
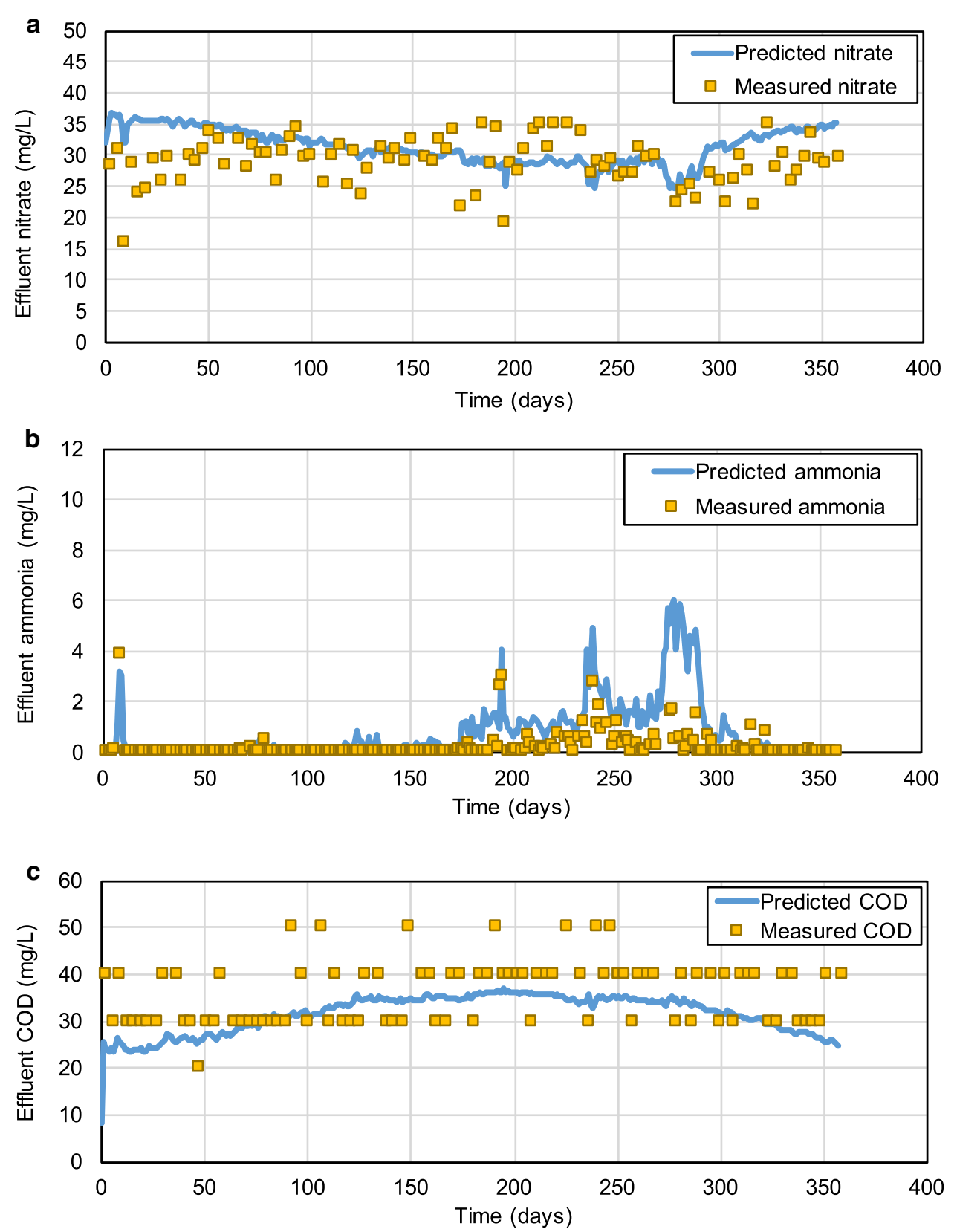

general profile matched the collected data. The high nitrate values observed in the secondary effluent of the studied treatment plant (Fig. 5) can be explained by the high DO in the treatment lines (well above $2 \mathrm{mg} \mathrm{L}^{-1}$ ) throughout the year, rendering it impossible for denitrification to occur. The measured nitrite concentrations in the secondary effluent were $<0.5 \mathrm{mg} \mathrm{L}^{-1}$, except during the winter where it rose slightly (not shown), indicating that the activated sludge plant under study is a fully nitrifying plant as most of the ammonia is completely converted to nitrate. Since the presence of nitrifying biomass and other slowly growing biomass is expected to enhance the removal of micropollutants through biodegradation [22], capturing the general profile of ammonia removal is essential for the prediction of the fate of micropollutants.

\section{Conclusion}

In this study, an activated sludge model was calibrated with 1-year, full-scale conventional pollutants measurements and a relatively small, dedicated 3-day detailed measurement campaign as a preparatory step for the subsequent fate modelling of micropollutants. The following conclusions and insights on the modelling of the fate of conventional pollutants in an activated sludge process were reached: 
1. Proper characterization of incoming TSS by accounting for the colloidal matter that is not included in the TSS measurements was found to be one of the main influencing factors on the solids balance.

2. The chemically enhanced primary treatment was considered to seasonally influence the particulate composition of the primary effluent, requiring special considerations during the characterization of the incoming TSS fraction to the activated sludge unit.

3. The Bürger-Diehl model for the secondary settler resulted in improved calibration of the effluent TSS compared to the Takács model, which is related to the inclusion of additional layers to model the outlet boundaries.

4. Careful calibration of the solids balance through detailed influent characterization and appropriate selection of the settler model allowed the measured nutrient profiles in the effluent to be captured by the model using default ASM parameters.

The routine measurements available from the WWTP based on 24-h composite samples were proven to be sufficient to successfully model the general yearly profiles of WAS TSS, effluent TSS, DO and nutrients. Since these variables are linked to the main removal processes of micropollutants (i.e. through SRT, aeration and solids balance), it is shown that the measurement effort and resources required for the conventional modelling that is performed as a preliminary step for the calibration of the micropollutant model can remain limited.

Acknowledgements The authors thank the staff at the Guelph WWTP for their help in providing the data. We gratefully acknowledge the McGill Engineering Doctoral Award for supporting Zeina Baalbaki. Funding for this study was provided by a research Grant to Viviane Yargeau (PI) and colleagues (Chris Metcalfe and Peter Vanrolleghem) from the Natural Sciences and Engineering Research Council (NSERC) of Canada through the Strategic Grants Program (430646-2012). Peter Vanrolleghem holds the Canada Research Chair on Water Quality Modelling.

\section{References}

1. Mulder A, Coen F, Vanderhaegen B, Boonen I, Vanrolleghem PA, Van Meenen P (1997) Advanced wastewater treatment: nutrient removal and anaerobic processes. Improved design and control of industrial and municipal nutrient removal plants using dynamic models. Water Sci Technol 35(10):53-61. doi:10.1016/ S0273-1223(97)00217-5

2. Demey D, Vanderhaegen B, Vanhooren H, Liessens J, Van Eyck L, Hopkins L, Vanrolleghem PA (2001) Validation and implementation of model based control strategies at an industrial wastewater treatment plant. Water Sci Technol 44(2-3):145-153

3. Printemps C, Baudin A, Dormoy T, Zug M, Vanrolleghem PA (2004) Optimisation of a large WWTP thanks to mathematical modelling. Water Sci Technol 50(7):113-122
4. Weijers SR, De Jonge J, Van Zanten O, Benedetti L, Langeveld J, Menkveld HW, Van Nieuwenhuijzen AF (2012) Cost effective and integrated optimization of the urban wastewater system Eindhove. Water Pract Technol. doi:10.2166/wpt.2012.036

5. Coen F, Vanderhaegen B, Boonen I, Vanrolleghem PA, Van Eyck L, Van Meenen P (1996) Nitrogen removal upgrade of a wastewater treatment plant within existing reactor volumes: a simulation supported scenario analysis. Water Sci Technol 34(3):339-346. doi:10.1016/0273-1223(96)00591-4

6. Guo L, Vanrolleghem PA (2014) Calibration and validation of an activated sludge model for greenhouse gases No. 1 (ASMG1): prediction of temperature-dependent $\mathrm{N}_{2} \mathrm{O}$ emission dynamics. Bioprocess Biosyst Eng 37(2):151-163. doi:10.1007/s00449-013-0978-3

7. Henze M, Gujer W, Mino T, Matsuo T, Wentzel MC, Marais GVR, Van Loosdrecht MCM (1999) Activated sludge model No. 2D, ASM2D. Water Sci Technol 39(1):165-182. doi:10.1016/ S0273-1223(98)00829-4

8. Smith M, Dudley J (1998) Dynamic process modelling of activated-sludge plants. J Chart Inst Water Environ Manag 12(5):346-356. doi:10.1111/j.1747-6593.1998.tb00196.x

9. Takács I, Patry GG, Nolasco D (1991) A dynamic model of the clarification-thickening process. Water Res 25(10):1263-1271. doi:10.1016/0043-1354(91)90066-Y

10. Bürger R, Diehl S, Nopens I (2011) A consistent modelling methodology for secondary settling tanks in wastewater treatment. Water Res 45(6):2247-2260. doi:10.1016/j.watres.2011.01. 020

11. Bürger R, Diehl S, Farås S, Nopens I (2012) On reliable and unreliable numerical methods for the simulation of secondary settling tanks in wastewater treatment. Comput Chem Eng 41:93-105. doi:10.1016/j.compchemeng.2012.02.016

12. Torfs E, Maere T, Bürger R, Diehl S, Nopens I (2015) Impact on sludge inventory and control strategies using the Benchmark Simulation Model No. 1 with the Bürger-Diehl settler model. Water Sci Technol 71(10):1524-1535. doi:10.2166/wst.2015.122

13. Rieger L, Gillot S, Langergraber G, Ohtsuki T, Shaw A, Takacs I, Winkler S (2013) Guidelines for using activated sludge models. IWA Publishing, London

14. Clouzot L, Choubert J-M, Cloutier F, Goel R, Love NG, Melcer $\mathrm{H}$, Ort C, Patureau D, Plósz BG, Pomiès M, Vanrolleghem PA (2013) Perspectives on modelling micropollutants in wastewater treatment plants. Water Sci Technol 68(2):448-461. doi:10.2166/ wst.2013.272

15. Plósz BG, Langford KH, Thomas KV (2012) An activated sludge modeling framework for xenobiotic trace chemicals (ASM-X): assessment of diclofenac and carbamazepine. Biotechnol Bioeng 109(11):2757-2769. doi:10.1002/bit.24553

16. Urase T, Kikuta T (2005) Separate estimation of adsorption and degradation of pharmaceutical substances and estrogens in the activated sludge process. Water Res 39(7):1289-1300. doi:10. 1016/j.watres.2005.01.015

17. Dionisi D, Bertin L, Bornoroni L, Capodicasa S, Papini MP, Fava F (2006) Removal of organic xenobiotics in activated sludges under aerobic conditions and anaerobic digestion of the adsorbed species. J Chem Technol Biotechnol 81(9):1496-1505. doi:10. 1002/jctb. 1561

18. Lindblom E, Press-Kristensen K, Vanrolleghem PA, Mikkelsen PS, Henze M (2009) Dynamic experiments with high bisphenola concentrations modelled with an ASM model extended to include a separate XOC degrading microorganism. Water Res 43(13):3169-3176. doi:10.1016/j.watres.2009.04.030

19. Vezzaro L, Benedetti L, Gevaert V, De Keyser W, Verdonck F, De Baets B, Nopens I, Cloutier F, Vanrolleghem PA, Mikkelsen PS (2014) A model library for dynamic transport and fate of micropollutants in integrated urban wastewater and stormwater 
systems. Environ Model Softw 53:98-111. doi:10.1016/j.envsoft. 2013.11.010

20. Rogers HR (1996) Sources, behaviour and fate of organic contaminants during sewage treatment and in sewage sludges. Sci Total Environ 185(1-3):3-26. doi:10.1016/0048-9697(96)05039-5

21. Kreuzinger N, Clara M, Strenn B, Kroiss H (2004) Relevance of the sludge retention time (SRT) as design criteria for wastewater treatment plants for the removal of endocrine disruptors and pharmaceuticals from wastewater. Water Sci Technol 50(5):149-156

22. Suarez S, Lema JM, Omil F (2010) Removal of pharmaceutical and personal care products (PPCPs) under nitrifying and denitrifying conditions. Water Res 44(10):3214-3224. doi:10.1016/j. watres.2010.02.040

23. Rice EW, Baird RB, Eaton AD, Clesceri LS (2012) Standard methods for the examination of water and wastewater, 22nd edn. APHA/AWWA/WEF, Washington, DC

24. Vanrolleghem PA, Nopens I (2014) Wastewater Treatment. In: Price RK, Vojinovic Z (eds) Urban hydroinformatics: data, models, and decision support for integrated urban water management. IWA Publishing, London, pp 371-421

25. Baalbaki Z, Sultana T, Maere T, Vanrolleghem PA, Metcalfe CD, Yargeau V (2016) Fate and mass balance of contaminants of emerging concern during wastewater treatment determined using the fractionated approach. Sci Total Environ 573:1145-1158. doi:10.1016/j.scitotenv.2016.08.073

26. STOWA (1996) Methods for wastewater characterisation, inventory and guidelines (in Dutch), STOWA report 97-23. Hageman Fulfilment, Zwijndrecht

27. Roeleveld PJ, Van Loosdrecht MCM (2002) Experience with guidelines for wastewater characterization in The Netherlands. Water Sci Technol 45(6):77-87
28. Melcer H, Dold PL, Jone RM, Bye CM, Takács I, Stensel HD, Wilson AW, Sun P, Bury S (2003) Methods for wastewater characterization in activated sludge modelling. Water Environment Research Foundation et IWA Publishing, Alexandria

29. Rousseau D, Verdonck F, Moerma O, Carrette R, Thoeye C, Meirlaen J, Vanrolleghem PA (2001) Development of a risk assessment based technique for design/retrofitting of WWTPs. Water Sci Technol 43(7):287-294

30. Henze M, Gujer W, Mino T, Van Loosdrecht MCM (2000) Activated sludge models ASM1, ASM2, ASM2d and ASM3. IWA Publishing, London

31. Copp JB (2002) The COST simulation benchmark-description and simulator manual. European Cooperation in the Field of Scientific and Technical Research, Luxembourg

32. Office of Water Programs (1980) Operation of wastewater treatment plants, Volume I, vol 1, 4th edn. California State University, Sacramento Foundation, California

33. Tik S, Vanrolleghem PA (2012) Gestion des eaux usées en temps de pluie-De l'alun en périodes critiques à la Ville de Québec (in French). Vecteur Environn:32-33

34. Balmat JL (1957) Biochemical oxidation of various particulate fractions of sewage. Sew Ind Wastes 29(7):757-761

35. Heukelekian H, Balmat JL (1959) Chemical composition of the particulate fractions of domestic sewage. Sew Ind Wastes 31(4):413-423

36. Ødegaard H (1992) Norwegian experiences with chemical treatment of raw wastewater. Water Sci Technol 25(12):255

37. Ødegaard H (2005) Combining CEPT and biofilm systems. In: IWA specialized conference on nutrient management in wastewater treatment processes and recycle streams, Krakow, 19-21 September 2005, pp 257-269 